\title{
Eculizumab for Gemcitabine-Induced Hemolytic Uremic Syndrome: A Novel Therapy for an Emerging Condition
}

\author{
Raphael Karkowsky, MD \\ Thomas Jefferson University, Raphael.karkowsky@jefferson.edu \\ Kinjal Parikh, MD \\ Thomas Jefferson University, Kinjal.parikh@jefferson.edu
}

\section{Follow this and additional works at: https://jdc.jefferson.edu/tmf \\ Part of the Medicine and Health Sciences Commons \\ Let us know how access to this document benefits you}

\section{Recommended Citation \\ Karkowsky, MD, Raphael and Parikh, MD, Kinjal (2015) "Eculizumab for Gemcitabine-Induced Hemolytic Uremic Syndrome: A Novel Therapy for an Emerging Condition," The Medicine Forum: Vol. 16 , Article 8. DOI: https://doi.org/10.29046/TMF.016.1.007 \\ Available at: https://jdc.jefferson.edu/tmf/vol16/iss1/8}

This Article is brought to you for free and open access by the Jefferson Digital Commons. The Jefferson Digital Commons is a service of Thomas Jefferson University's Center for Teaching and Learning (CTL). The Commons is a showcase for Jefferson books and journals, peer-reviewed scholarly publications, unique historical collections from the University archives, and teaching tools. The Jefferson Digital Commons allows researchers and interested readers anywhere in the world to learn about and keep up to date with Jefferson scholarship. This article has been accepted for inclusion in The Medicine Forum by an authorized administrator of the Jefferson Digital Commons. For more information, please contact: JeffersonDigitalCommons@jefferson.edu. 


\section{Eculizumab for Gemcitabine-Induced Hemolytic Uremic Syndrome: A Novel Therapy for an Emerging Condition}

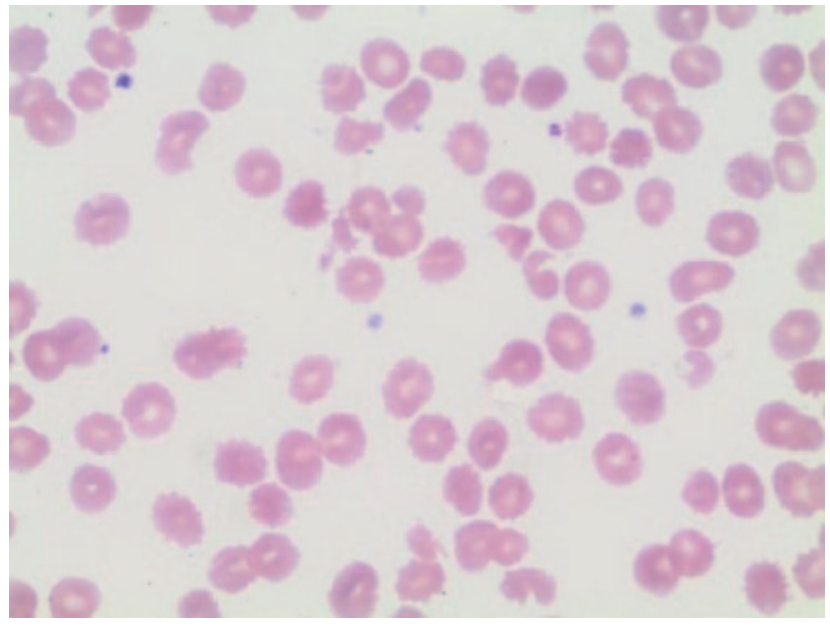

Figure 1. Microscopic appearance of peripheral blood smear from patient (×100), showing increased schistocytes, echinocytes, and acanthocytes

\section{INTRODUCTION}

Atypical hemolytic uremic syndrome (aHUS), a thrombotic microangiopathy (TMA), is a disease characterized by hemolytic anemia, thrombocytopenia, and renal impairment. Gemcitabine, a commonly used chemotherapy, is emerging as a cause of aHUS. Although rare, the morbidity and mortality can be significant. Few studies have explored the use of eculizumab, an anti-C5 monoclonal antibody as a potential therapy for gemcitabine-induced aHUS.

\section{CASE PRESENTATION}

A 45 year old Caucasian male with metastatic urothelial carcinoma was started on weekly gemcitabine (1000 $\mathrm{mg} / \mathrm{m}^{2}$ per dose) to treat recurrent disease. During his seventh cycle, he was hospitalized for hypertension, acute kidney injury, and anemia. Laboratory data at that time revealed a hemoglobin of $6.2 \mathrm{~g} / \mathrm{dL}$ (reference range 14.0-17.0 g/dL) and a platelet count of $70 \times 10^{9} / \mathrm{L}$ (reference range 140-400 $10^{\circ} / \mathrm{L}$ ). Hemolysis was suggested by an elevated lactate dehydrogenase (LDH)

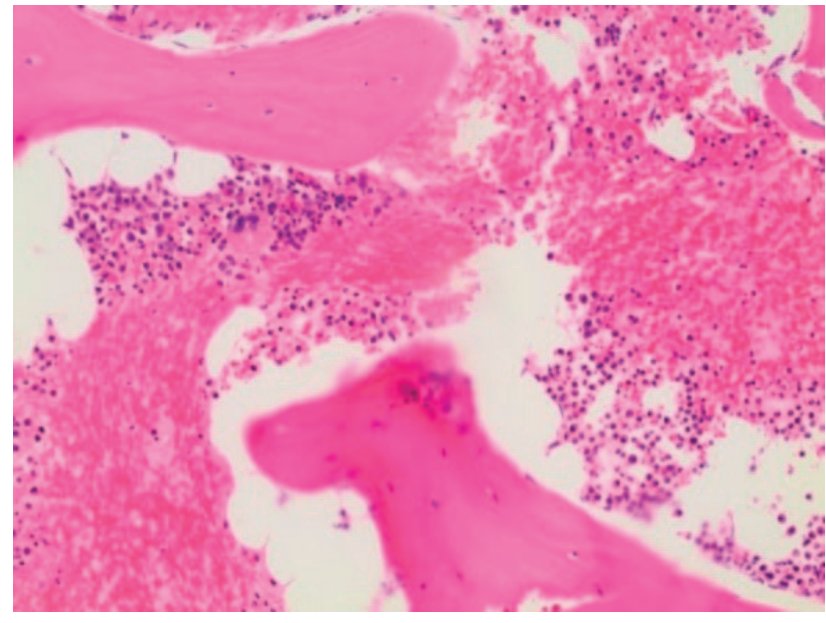

Figure 2. Microscopic appearance of bone marrow biopsy from patient $(\times 20)$, showing hypercellular bone marrow with trilineage hematopoiesis and no evidence of dysplasia or metastatic disease

of $420 \mathrm{IU} / \mathrm{L}$ (reference range 125-240 IU/L), undetectable haptoglobin, and the presence of schistocytes on the peripheral smear (see Figure 1). Creatinine was elevated to $2.8 \mathrm{mg} / \mathrm{dL}$ (reference range $0.7-1.4 \mathrm{mg} / \mathrm{dL}$ ) and an ADAMTS-13 (A disintegrin and metalloproteinase with a thromboSpondin type 1 motif, member 13) returned as normal. The patient was diagnosed with gemcitabineinduced aHUS. Gemcitabine was discontinued, and the patient was started on steroids. Two weeks later, he presented with generalized tonic-clonic seizures, uncontrolled hypertension, and worsening renal failure. His labs on admission showed continued hemolysis and thrombocytopenia. In light of the patient's poor response to steroids, the decision was made to start eculizumab.

\section{DIFFERENTIAL DIAGNOSIS}

Gemcitabine-induced aHUS is often a difficult diagnosis to make. In this case, it was distinguished from thrombotic thrombocytopenic purpura (TTP) by normal levels of ADAMTS-13. Furthermore, normal coagulation studies and the lack of bleeding made disseminated intravascular 
coagulation unlikely. Bone marrow biopsy showed trilineage, hypercellular hematopoiesis, suggesting peripheral destruction rather than myelosuppression from chemotherapy (see Figure 2). Idiopathic thrombocytopenic purpura was a less likely diagnosis, as the presence of schistocytes suggested microangiopathy.

\section{OUTCOME AND FOLLOW-UP}

The patient was started on eculizumab and received a course of six doses. His treatment was complicated by a multifocal pneumonia that developed four days after receiving his second dose. His labs two months after starting treatment showed an improved platelet count of $118 \times 10 \%$ L. Although he remained anemic, his labs did not show evidence of further hemolysis (see figure 3). The patient's creatinine remained elevated at $6.2 \mathrm{mg} /$ $\mathrm{dL}$, and he was started on renal replacement therapy (RRT). The patient died three months after initiation of eculizumab therapy secondary to complications of his underlying malignancy.

\section{DISCUSSION}

The vast majority of HUS are preceded by a bout of infectious diarrhea, usually due to Escheria coli; $90 \%$ of cases are not, and are therefore termed atypical. ${ }^{1}$ This atypical form of HUS is associated with factors such as human immunodeficiency virus infection, malignancy, organ transplantation, pregnancy, or medications, including anti-neoplastic drugs. ${ }^{1.2}$ Recently, gemcitabine, a $2^{\prime}, 2^{\prime}$-difluorodeoxycytidine, has surfaced as a cause of atypical HUS. The incidence of gemcitabine-induced aHUS ranges from 0.015 to $1.4 \%^{2}$ per current case series reviews.

Pathologically, aHUS is identical to the typical form. Histology generally shows arteriole and capillary thickening, a swollen endothelium, and proteinaceous deposits in the subendothelium. A blood smear will typically show schistocytes. The kidneys are most commonly involved, but the brain, lung, pancreas, and gastrointestinal tract may be affected as well. Dysregulation of the alternative complement cascade leads to the formation of the final membrane-attack complex (MAC) and subsequent endothelial injury, which plays a pivotal role. ${ }^{1}$

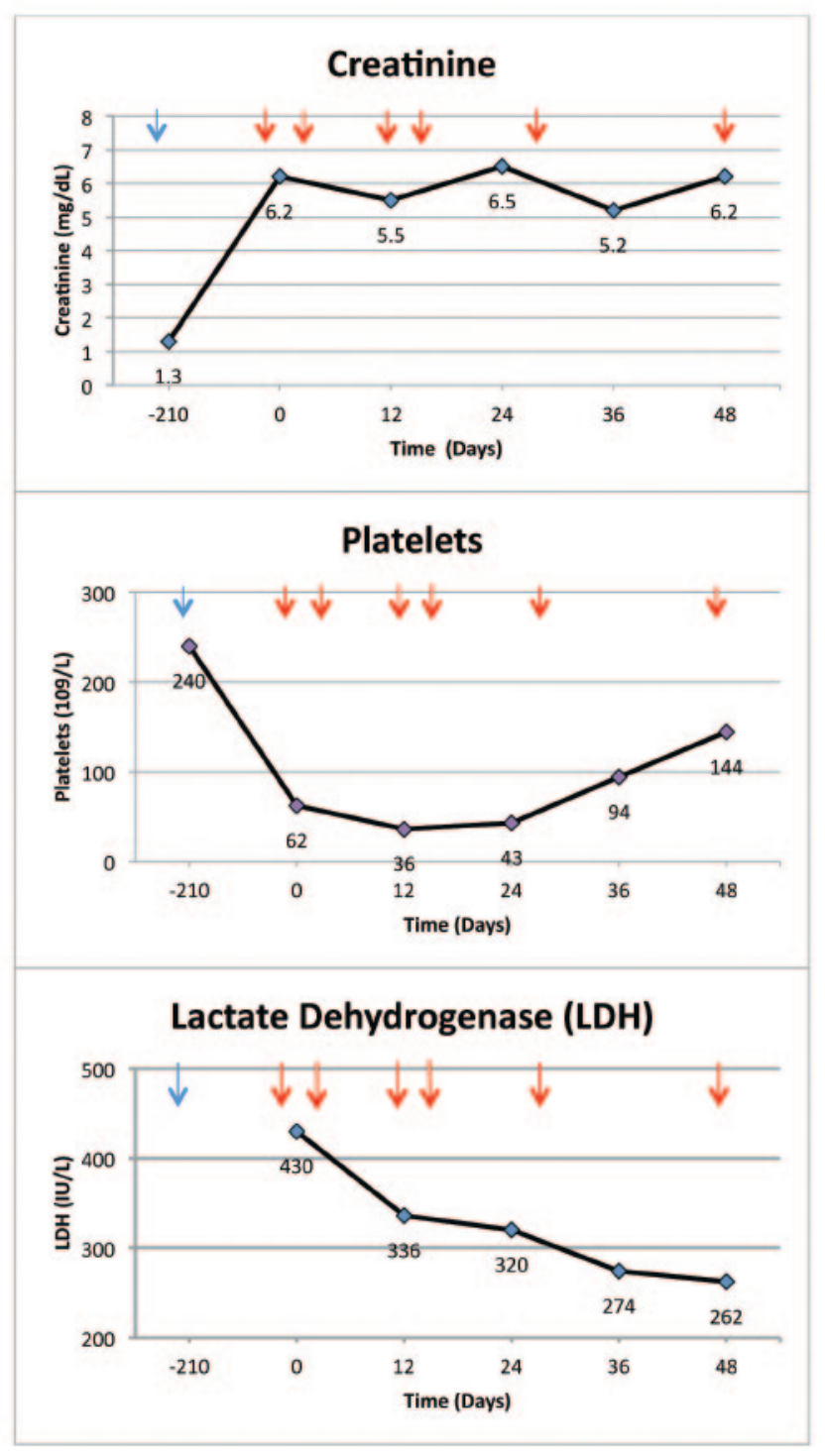

Figure 3. Chart Showing response to eculizumab treatment in gemcitabine-induced thrombotic microangiopathy. Red arrows represent eculuzimab administration and blue arrows represent gemcitabine administration.

The most agreed upon treatment for gemcitabineinduced aHUS remains discontinuation of the drug. Other therapies, such as therapeutic plasma exchange (TPE), demonstrate less reliable effectiveness, as shown in a recent meta-analysis by Gore and colleagues, which concluded that the use of TPE is not associated with an improved rate of recovery. ${ }^{8}$ Recent case reports have also suggested a potential role for splenectomy ${ }^{8}$ or rituximab.? Novel therapies such as Complement Factor $\mathrm{H}$, a regulatory protein in the alternative complement 
cascade, is currently being studied as a treatment for patients suffering from aHUS who are deficient in this protein.

The safety of eculizumab is still being determined. In this case, the patient developed multifocal pneumonia just days after receiving his second dose of eculizumab. Inhibition of MAC formation by eculizumab reduces defense against encapsulated organisms, specifically those that cause pneumonia. ${ }^{10}$ Therefore, it is reasonable to suspect, that eculizumab may have served as a risk factor in our patient's development of this complication.

Only a few studies have investigated the treatment of gemcitabine-induced HUS with eculizumab. Similar to the studies by Starck and colleagues and Legendre and colleagues, this case study highlights eculizumab's effectiveness in improving microangiopathy and the resultant thrombocytopenia and hemolysis in aHUS. Those studies, although promising, were somewhat confounded by prior use of TPE, which was not true in our case. Lohr and colleagues' case series, seemed to suggest that eculizumab is an effective therapy for the kidney damage sustained in aHUS. In our case study, however, the patient did not demonstrate the same improvement in kidney function, and his kidney disease ultimately progressed to the point of needing RRT. The role of eculuzimab in treating aHUS and its efficacy is still being defined.

\section{KEY POINTS}

The above case demonstrates eculizumab's partial effectiveness in treating the microangiopathy in gemcitabine-induced aHUS. Although the patient demonstrated recovery in platelet count and resolution of his hemolysis, he showed only limited improvement in renal function. Moreover, the patient's course of therapy was complicated by pneumonia, which along with infections from other encapsulated organisms, may represent a possible side effect of the medication. Further research, specifically, larger scale prospective studies, are needed to better assess the degree of efficacy and safety of eculizumab for gemcitabineinduced TMA.

\section{REFERENCES}

1. Noris, Marina, and Giuseppe Remuzzin. "Atypical Hemolytic Uremic Syndrome." The New England Journal of Medicine 36, no. 17 (2009): 1676-87.

2. Zupanic, Melanie, Prabodh C. Shah, and Farheen Shah-Khan "Gemcitabine-Associated Thrombotic Thrombocytopenic Purpura." Lancet Oncology 8 (2007): 634-641.

3. Fung, Man C., Anna Maria Storniolo, Binh Nguyen, Michael Arning, William Brookfield, and James Vigil. "A Review of hemolytic Uremic Syndrome in Patients Treated with Gemcitabine Therapy." Cancer 9, no. 135 (1999): 2023-2032.

4. Brodowicz, Thomas, Silvana Breitendeder, Christoph Wiltschke, and Christoph C Zielinski. "Gemcitabine-Induced Hemolytic Uremic Syndrome: a Case Report." Journal of the National Cancer Institute 89, no. 24 (1997): 1895-1896.

5. Smet, D. De, K. Jochmans, and B. Neyns. "Development of Thrombotic Thrombocytopenic Purpura After a Single Dose of Gemcitabine." Annals of Hematology 87 (2008): 495-496.

6. Nackaerts, K, M Daenen, J Vansteenkiste, A Vandelvelde, P Van Bleyenbergh, and M Demedts. "Hemolytic-Uremic Syndrome Caused by Gemcitabine." Annalsof Oncology 9 (1998): 1355-1356.

7. Bharthuar, Anubha, et al. "Rituximab-Based Therapy for Gemcitabine-Induced Hemolytic Uremic Syndrome in a Patient with Metastatic Pancreatic Adenocarcinoma: A Case Report." Cancer Chemotherapeutics and Pharmacology 64 (2009): 177-181.

8. Robinson, Andrew, and William F. Clark. "A Case Report of Gemcitabine Treatment for Duodenal Cancer: The Good (A Sustained Response) and The Bad (Life Threatening Refractory Thrombotic Thrombocytopenic Purpura)." Journal of Gastrointestinal Cancer 41 (2010): 71-74.

9. Legendre, C. M., et al. "Terminal Complement Inhibitor Eculizumab in Atypical Hemolytic-Uremic Syndrome." The New England Journal of Medicine 368, no. 23 (2013): 2169-2181. (Al Ustwani, et al., 2014)

10. Food and Drug Administration. Soliris (eculuzimab). Prescribing Information, FDA Center for Drug Evaluation and Research, 2007.

11. Starck, Michael, and Clemens-Martin Wendtner. "Use of Eculizumab in Refractory Gemcitabine-induced Thrombotic Microangiopathy." British Journal of Haematology (2013): N/a. Br J Haematology. Web. 6 Oct. 2014. http://www.ncbi.nlm.nih. gov/pubmed/24666021\#

12. Al Ustwani, et al. "Eculizumab Therapy for Gemcitabine Induced Hemolytic Uremic Syndrome: Case Series and Concise Review." Journal of Gastrointestinal Oncology (2014): n. pag. Web. 6 Oct. 2014. www.ncbi.nlm.nih.gov/pubmed/24490050

13. Gore, Ethan Mccaleb, Benjamin Scott Jones, and Marisa B. Marques. "Is Therapeutic Plasma Exchange Indicated for Patients with Gemcitabine-induced Hemolytic Uremic Syndrome?" Journal of Clinical Apheresis 24.5 (2009): 209-14. Web. 10 June 2014 